\title{
ACTIVE TEACHING-LEARNING METHODOLOGY TO APPROACH CARBOHYDRATE AND LIPID METABOLISM: AN INTERDISCIPLINARY STRATEGY THAT INVOLVED THE MOODLE TOOL IN THE DEVELOPMENT OF PROBLEM BASED LEARNING
}

\author{
Borges, J. M. P. ${ }^{2}$, El Bacha, R. ${ }^{2}$, COSTA, M. F.'.; FREIRE, E' \\ 1.Programa de Pós-graduação em Processos Interativos dos Órgãos e Sistemas, Departamento de Biofunção, Instituto de \\ Ciências da Saúde, UFBA, Salvador, Brazil; '2. Programa de Pós-graduação em Imunologia, Departamento de Biofunção, \\ Instituto de Ciências da Saúde, UFBA, Salvador, Brazil
}

Highlight the relevance of topics studied for professional practice and associate approaches provided by different areas of knowledge are pointed as essential aspects for significant learning. Contextualize the study of metabolic pathways, linking the clinical use and expanding the vision with the approach of cellular and molecular biology discipline was the motivation for the development of the strategy described and evaluated here. In this work, starting from the concept of active methodology of teaching and learning was developed a methodological strategy to approach the carbohydrate and lipid metabolism. This strategy included: questioning the content through the clinical case study on diabetes mellitus and hypercholesterolemia, individual and collective study in the external space the classroom with the help of Moodle tool, classroom discussion accompanied by the teacher, preparation of seminar, evaluation of the content through individual written test and evaluation of the method. Analysis of student involvement with method indicates an average frequency of $98 \%$ in the practical class of Biochemistry discipline, effective participation in the preparation of seminars, an increase of 2 points in average of individual written evaluation. As for the fact that the cases were studied in two curricular components, the answers show that $92 \%$ of students feel more compression. Only $6 \%$ of students think unnecessary to interdisciplinary approach. As for the different steps of the method, the answers show that $99 \%$ of students consider how relevant the initial self-study and discussions in class. However, only $50 \%$ of students appreciated the use of Moodle tool. Thus, student responses indicated the perception of the effectiveness of the method for their ability to: stimulate interest in learning, stimulate the search for answers through research and the building of learning.

Keywords: active methodology, teaching biochemistry, metabolism 